Article

\title{
Development of a Physical Model of Thermovoltaic Effects in the Thin Films of Zinc Oxide Doped with Transition Metals
}

\author{
Igor Pronin ${ }^{1,2, *}$, Nadejda Yakushova ${ }^{1}$, Igor Averin ${ }^{1}$, Andrey Karmanov ${ }^{1}$, \\ Vyacheslav Moshnikov ${ }^{2}$ and Dimitre Dimitrov ${ }^{3}$ \\ 1 Department of Nano- and Microelectronics, Penza State University, Penza 440026, Russia; \\ yand93@mail.ru (N.Y.); nano-micro@mail.ru (I.A.); starosta07km1@mail.ru (A.K.) \\ 2 Department of Micro- and Nanoelectronics, St-Petersburg State Electrotechnical University, St. Petersburg \\ 197376, Russia; vamoshnikov@mail.ru \\ 3 Department of General and Inorganic Chemistry, Sofia University, St. Kliment Ohridski, Sofia 1504, Bulgaria; \\ dtsenov@wmail.chem.uni-sofia.bg \\ * Correspondence: pronin_i90@mail.ru; Tel.: +7-987-502-59-85
}

Received: 9 October 2018; Accepted: 26 November 2018; Published: 27 November 2018

check for updates

\begin{abstract}
A model of the thermovoltaic effect emergence in $\mathrm{ZnO} / \mathrm{ZnO}<\mathrm{Me}>(\mathrm{Me}=\mathrm{Cu}, \mathrm{Fe})$, sandwich structures has been developed in the article. The samples were made by the sol-gel method. When they were uniformly heated in a laboratory furnace in the temperature range of $200-300{ }^{\circ} \mathrm{C}$, there an electromotive force (EMF) of $-7 \sim 10 \mathrm{mV}$, not associated with the Seebeck effect, emerged. The developed physical mechanisms of the effect emergence consist of the following well-known fact: iron and copper coexist in zinc oxide in two states, namely, $\mathrm{Fe}^{2+}$ and $\mathrm{Fe}^{3+}$ (donor), and $\mathrm{Cu}^{2+}$ and $\mathrm{Cu}^{+}$ (acceptor). During the heating of the $\mathrm{ZnO} / \mathrm{ZnO}-\mathrm{Me}$ system, the concentration of charge carriers in the layers will increase, while in the upper layer its value will be larger because of the presence of electrically active impurities. At room temperatures, Coulomb forces retain an electron that is located on the $\mathrm{Fe}^{2+}$ ion, as well as a hole on $\mathrm{Cu}^{2+}$ ion, and the main states undergo ionization. However, as the temperature increases, the carrier concentration can reach a critical level, when they can screen the ion charge (the Debye screening radius decreases to the Bohr radius of the impurity). In this case, an abrupt collective endothermic process of ionization of multivalent impurities takes place, accompanied by the appearance of a concentration gradient of free carriers in the sample, and accordingly, the emergence of an electromotive force. Quantitative calculations of the critical temperature, at which the onset of EMF generation is observed, performed within the framework of the developed models.
\end{abstract}

Keywords: thermovoltaic effect; zinc oxide; spontaneous voltage generation; metal-insulator transition

\section{Introduction}

A thermovoltaic effect is a phenomenon of the appearance of an electromotive force under uniform heating of semiconductor materials without a temperature gradient that is associated with a nonuniform distribution of the impurity in the semiconductor. This effect was first observed in SmS and described in [1]. Apparently, it is the representative of a number of spontaneous voltage generation effects, explained by various physical mechanisms. Currently, spontaneous voltage generation (SVG) is an effect involving a wide range of related phenomena in various materials associated with the emergence of an electromotive force in samples under uniform heating without a temperature gradient. The prospect of its practical use is connected with the possibility of developing sources for alternative 
energy, as well as sensors for monitoring the state of the environment. This effect was first discovered in 1976 in crystals of stoichiometric iron sulfide $\mathrm{FeS}$ at a phase transition of $150{ }^{\circ} \mathrm{C}$ [2], while the magnitude of the resulting electromotive force was proportional to the rate of order-disorder transition. At present, the amount of materials in which this effect was observed is limited by SmS [3], TiNi [4], $\mathrm{La}\left(\mathrm{Fe}_{0.88} \mathrm{Si}_{0.12}\right)_{13}$ [5], $\mathrm{Pr}_{0.6} \mathrm{Ca}_{0.4} \mathrm{MnO}_{3}$ [6], metal-dielectric-semiconductor-metal (MDSM) structure [7], and some other components that are based on rare earth metals. In most cases, the effect is observed in the structural phase transition of the first kind. To explain the origin of the SVG, some physical mechanisms, including models of diffusion currents [4] and the motion of twin boundaries, have been developed. There are also models of the Seebeck effect, and temperature gradient is caused by the absorption or release of latent heat of the phase transition in the local parts of the samples [5]. The authors [3] explain the electromotive force generation in $\mathrm{SmS}$ by the emergence of semiconductor-metal phase transition in the local areas of the sample, by diffusion processes of the emerged excess carriers, and, as a consequence, by the emergence of the counteracting electric field of the appropriate intensity.

The authors of this paper first discovered the SVG in $\mathrm{ZnO} / \mathrm{ZnO}-\mathrm{Me}$ homojunctions $(\mathrm{Me}-\mathrm{Fe}, \mathrm{Cu})[8,9]$. To explain this effect, the Mott insulators theory has been applied. Thus, a change in the impurity valence in the sample takes place under a certain critical temperature, as well as the emergence of the excess carrier concentration in the doped region and their diffusion into the undoped part. There also the counteracting field and electromotive force appear as a result of this process. The authors' conclusions about the SVG existence in nanostructures based on non-uniformly doped zinc oxide have been experimentally confirmed by other scientific groups. In particular, the appearance of a thermovoltaic response in two-layer thin-film $\mathrm{ZnO} / \mathrm{ZnO}-\mathrm{Fe}$ structures with a maximum modulo value of $1200 \mu \mathrm{V}$ at a temperature of $673 \mathrm{~K}$ is shown in [10]. Somewhat later, this effect was observed in a solid solution $\mathrm{Si}_{1-x} \mathrm{Ge}_{x}(0 \leq x \leq 1)$ and in $n \mathrm{Si}_{-} p \mathrm{Si}_{1-x} \mathrm{Ge}_{x}$ heterostructures [11,12].

In References [3,6,7], the prospect of the SVG using for converters of thermal to electric energy, and various sensors (including gas sensors and bacteria) is outlined. For example, in polycrystalline SmS samples, the coefficient of converting thermal to electric energy, according to [13], is in the range of $7.5 \%-28 \%$, which suggests the possibility of creating a new generation of converters.

Thus, the analysis of literature shows that, apparently, the SVG is a family of the related phenomena, the physics of which, however, is currently unclear. The purpose of this paper is to develop physical mechanisms of the thermovoltaic effect in zinc oxide non-uniformly doped with mixed-valence impurities ( $\mathrm{Cu}$ and $\mathrm{Fe}$ ).

\section{Materials and Methods}

To study the thermovoltaic effect, $\mathrm{ZnO} / \mathrm{ZnO}-\mathrm{Me}$ homojunctions, as obtained in the framework of sol-gel technology by the sol immersion method, were used as laboratory samples.

The following reagents were used as precursors for the synthesis of film-forming sols: zinc acetate dihydrate $\left(\mathrm{CH}_{3} \mathrm{COO}\right)_{2} \mathrm{Zn} \cdot 2 \mathrm{H}_{2} \mathrm{O}$, 2-methoxyethanol $\mathrm{CH}_{3} \mathrm{OCH}_{2} \mathrm{CH}_{2} \mathrm{OH}$, 2-aminoethanol $\mathrm{HOCH}_{2} \mathrm{CH}_{2} \mathrm{NH}_{2}$, iron nitrate nonahydrate $\mathrm{Fe}\left(\mathrm{NO}_{3}\right)_{3} \cdot 9 \mathrm{H}_{2} \mathrm{O}$, and copper acetate monohydrate $\left(\mathrm{CH}_{3} \mathrm{COO}\right)_{2} \mathrm{Cu} \cdot \mathrm{H}_{2} \mathrm{O}$ produced by Sigma-Aldrich ${ }^{\circledR}$, Saint Louis, MO, USA. The substrates were ceramic material Rubalit ${ }^{\circledR} 710\left(99.6 \% \mathrm{Al}_{2} \mathrm{O}_{3}\right)$ of $20 \mathrm{~mm} \times 10 \mathrm{~mm} \times 0.63 \mathrm{~mm}$ produced by CeramTec, Plochingen, Germany.

To obtain undoped $\mathrm{ZnO}$ films, the following procedure was used: $10 \mathrm{~g}$ of $\left(\mathrm{CH}_{3} \mathrm{COO}\right)_{2} \mathrm{Zn} \cdot 2 \mathrm{H}_{2} \mathrm{O}$, $20 \mathrm{~mL}$ of $\mathrm{CH}_{3} \mathrm{OCH}_{2} \mathrm{CH}_{2} \mathrm{OH}$ and $3.2 \mathrm{~mL}$ of $\mathrm{HOCH}_{2} \mathrm{CH}_{2} \mathrm{NH}_{2}$ were mixed in a round-bottomed flask and stirred for $15 \mathrm{~min}$ at room temperature until the zinc acetate dissolved completely. In a second step, the solution was stirred for $60 \mathrm{~min}$ at a temperature of $60^{\circ} \mathrm{C}$ using a magnetic stirrer (PE-6110, Ekros-Analitika, Saint Petersburg, Russia). The resulting sol was ripened for $24 \mathrm{~h}$ at room temperature and was deposited onto the substrates by the dip-coating method.

The formation of undoped $\mathrm{ZnO}$ layer was carried out by three successive immersions of $2 / 3$ substrate area into the sol. After each dive, the structure was dried at $80^{\circ} \mathrm{C}$ for $30 \mathrm{~min}$. The final annealing was carried out for $60 \mathrm{~min}$ at $500{ }^{\circ} \mathrm{C}$. 
The preparation of film-forming sols for $\mathrm{ZnO}-\mathrm{Me}$ layers was carried out in the same manner as for pure $\mathrm{ZnO}$, but in the first stage of mixing the precursors, appropriate additives were introduced: for $\mathrm{ZnO}-\mathrm{Cu}$ films- $\left(\mathrm{CH}_{3} \mathrm{COO}\right)_{2} \mathrm{Cu} \cdot \mathrm{H}_{2} \mathrm{O}(0.273 \mathrm{~g}$ for 3 at. $\% \mathrm{Cu})$; for $\mathrm{ZnO}-\mathrm{Fe}$ films- $\mathrm{Fe}\left(\mathrm{NO}_{3}\right)_{3} \cdot 9 \mathrm{H}_{2} \mathrm{O}$ (0.552 $\mathrm{g}$ for 3 at. $\% \mathrm{Fe})$.

The formation of a metal-doped zinc oxide layer was carried out in a manner that was similar to the formation of the lower layer, but the $2 / 3$ substrate area was immersed in the sol from the opposite side. Thus, the overlap of the upper and lower layers was $1 / 3$ of the substrate area. The thickness of the upper layer was controlled by the number of immersions in the sol. $\mathrm{ZnO}-\mathrm{Me}$ films obtained by two $(\mathrm{ZnO}-\mathrm{Cu}(2)$ and $\mathrm{ZnO}-\mathrm{Fe}(2))$ and three $(\mathrm{ZnO}-\mathrm{Cu}(3)$ and $\mathrm{ZnO}-\mathrm{Fe}(3))$ immersions were used for the studies.

Heating of the samples took place in a tube furnace, inside which a predetermined temperature was maintained without its gradient. Measurement of the generated electromotive force was carried out using pressure point contacts made of gold (Figure 1a). Temperature control of the samples was carried out prior to each measurement at a given temperature for $8 \mathrm{~h}$. It should also be noted that no illumination of the samples in the tube furnace was made.

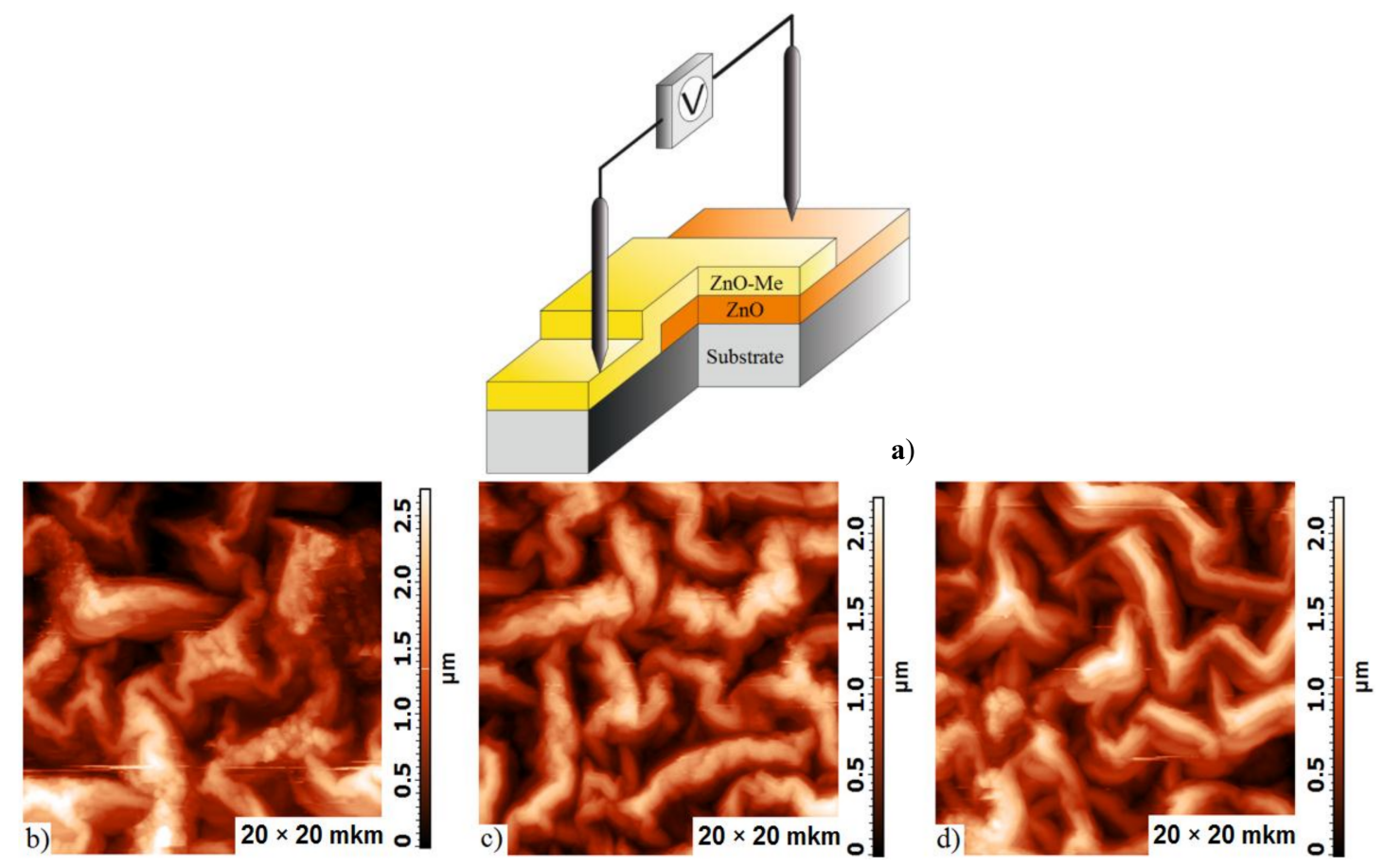

Figure 1. A scheme of the experiment (a); surface morphology of $\mathrm{ZnO}$ (b); $\mathrm{ZnO}-\mathrm{Fe}$ (c); and $\mathrm{ZnO}-\mathrm{Cu}$ (d) samples.

Investigation of the surface morphological structure of the obtained films was performed using an atomic force microscope NTEGRA Therma (NT-MDT, Zelenograd, Russia).

\section{Results and Discussion}

3.1. Mechanism for the Emergence of an Electromotive Force during the Heating of $\mathrm{ZnO} / \mathrm{ZnO}-\mathrm{Me}$ Homojunctions without an External Temperature Gradient

Figure $1 \mathrm{~b}-\mathrm{d}$ shows the structure of the samples studied, as obtained by atomic force microscopy. Image analysis of the surface morphology shows that in all cases the films have a three-dimensional structure with a typical diameter of the branches being 1-2 $\mu \mathrm{m}$. All of the branches are hierarchically assembled from nanocrystals having a fractal nature and formed during the maturation of the sol. 
Figure 2 shows the experimental results of the temperature dependence of the electromotive force arising in the samples. We note once again that the samples were heated without a temperature gradient, and before measuring the EMF, temperature control has been carried out for $8 \mathrm{~h}$ at each point. After this thermal equilibrium was established, a short circuit of the output electrical contacts, leading to the disappearance of the EMF, occurred. However, after opening the contacts, a complete restoration of the initial electromotive force values was observed. It should also be noted that the obtained values of the EMF were preserved in the "heating-cooling" cycles.

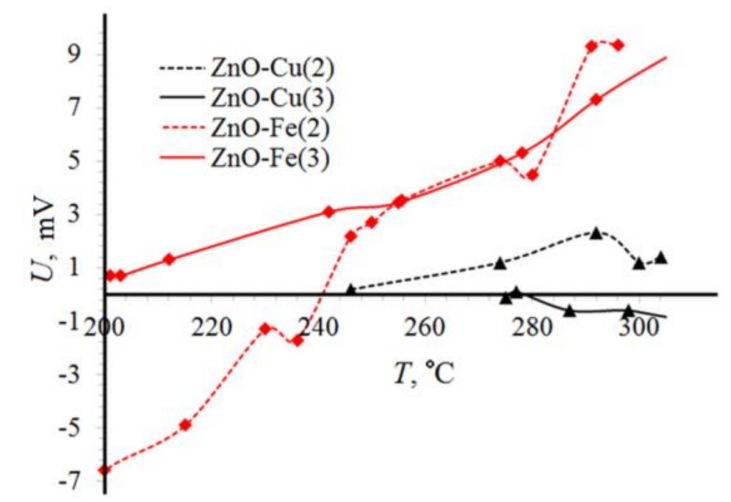

Figure 2. Temperature dependence of electromotive force in $\mathrm{ZnO} / \mathrm{ZnO}-\mathrm{Me}$ structures in the air atmosphere.

To explain the results obtained, we developed a model based on the "dielectric-conductor" transition in the upper heavily doped $\mathrm{ZnO}-\mathrm{Me}$ layer. On the one hand, the transition from insulating to metallic systems in semiconductor oxides (for example, $\mathrm{ZnO}, \mathrm{TiO}_{2}$ ) can be explained by an increase in the concentration of free charge carriers and the formation of a degenerate zone due to doping processes, as suggested by Mott [14]. However, in the case of high-alloyed semiconductor oxides, where there are both donor impurities and intrinsic electrically active point defects affecting the concentration of free charge carriers, the exact nature of the "insulator-conductor" transition is far from being understood. For example, in [15], an "insulator-conductor" transition was detected in the $\mathrm{ZnO}-\mathrm{Ga}$ system for the first time. The authors found that all gallium is in a state $\mathrm{Ga}^{3+}$ and is an effective donor. However, it was found that an increase in the conductivity of $\mathrm{ZnO}-\mathrm{Ga}$ thin films is a combined effect, associated both with the presence of gallium impurity and with oxygen vacancies acting as donors. However, pure zinc oxide shows only semiconductor behavior, which indicates the energy of oxygen vacancy levels is controlled by impurities, such as Ga. Thus, the introduction of gallium in $\mathrm{ZnO}$ leads to a change in the characteristics of oxygen vacancies and the metallic nature of conductivity. In Reference [16], an "insulator-metal" transition was observed in the ZnO-Fe system. The authors found that iron is in the zinc oxide matrix in two states, $\mathrm{Fe}^{2+}$ and $\mathrm{Fe}^{3+}$. It was shown that the main contribution to the metallic nature of the films is made by the ionization of $\mathrm{Fe}^{3+}$ state, replacing zinc cations in the crystal lattice. However, in the paper it was noted that the material may also have other sources of free charge carriers, for example, oxygen vacancies and interstitial zinc, which complement the effect of $\mathrm{Fe}^{3+}$. In the paper [17], the "insulator-metal" transition in thin $\mathrm{ZnO}-\mathrm{Nb}$ films was investigated. The authors found that niobium is in a donor $\mathrm{Nb}^{5+}$ state in the position of zinc cations in the material. The films containing $0.41 \mathrm{at} \% \mathrm{Nb}$ showed metallic behavior at ambient temperature. The authors associated it with the formation of a degenerate zone arising from a high level of doping in the framework of the Mott model.

According to X-ray absorption spectroscopy, there is $\mathrm{Cu}^{+}$(main), $\mathrm{Cu}^{2+}$ and $\mathrm{Fe}^{3+}$ (main), $\mathrm{Fe}^{2+}$ states, respectively, in $\mathrm{ZnO}-\mathrm{Cu}$ and $\mathrm{ZnO}-\mathrm{Fe}$ samples (the details of the zone diagram are presented in [8]). During the heating of the $\mathrm{ZnO} / \mathrm{ZnO}-\mathrm{Me}$ system, the concentration of charge carriers in the layers will be increased due to both ionization of the main forms of impurities in the material, and the ionization of its own point electrically active defects, first of all, oxygen vacancies, while its value 
will be larger in the upper layer because of the presence of electrically active impurities. At low temperatures, Coulomb forces retain an electron that is located on the $\mathrm{Fe}^{2+}$ ion, as well as a hole in $\mathrm{Cu}^{2+}$, and the main states undergo ionization. However, as the temperature increases, the carrier concentration can reach a critical level when they can screen the ion charge (the Debye screening radius decreases to the Bohr radius of the impurity). In this case, a collective abrupt endothermic process of ionization of the minority impurity forms takes place [18]. A literature review shows that the collective change in the valence of transition-element cations in zinc oxide with the release of free electrons (for example, $\mathrm{Fe}^{2+} \rightarrow \mathrm{Fe}^{3+}+\mathrm{e}^{-} ; \mathrm{Mn}^{2+} \rightarrow \mathrm{Mn}^{3+}+\mathrm{e}^{-}$, etc.) is well known. For example, in the paper [19], collective transition processes of iron, manganese, and nickel bivalent cations to trivalent ones, when heated, are shown. It was found that the temperature of release depends both on the type of impurity, and on other features of the material (impurity concentration, surface structure and volume, etc.). In the studied samples, a collective transition $\mathrm{Fe}^{2+} \rightarrow \mathrm{Fe}^{3+}+\mathrm{e}^{-}$occurred at low temperatures (90-120 $\mathrm{K})$, and the transition $\mathrm{Mn}^{2+} \rightarrow \mathrm{Mn}^{3+}+\mathrm{e}^{-}$occurred at room temperature. It should be noted that we investigated the $\mathrm{ZnO} / \mathrm{ZnO}-\mathrm{Ga}$ system for the occurrence of a thermovoltaic effect; however, we did not find it. We believe this is due to the fact that gallium is in a single $\mathrm{Ga}^{3+}$ state in the material.

To be certain, let us discuss the $\mathrm{ZnO}-\mathrm{Fe}$ semiconductor (all the conclusions are valid for acceptor semiconductors). The initial increase in the electron concentration is mainly determined only by the ionization of iron ions $\mathrm{Fe}^{3+}$ and oxygen vacancies. Following the authors [16], we will assume that their contribution is not decisive; therefore, we neglect them in the framework of our quantitative model. Nevertheless, it should be understood that the influence of the own point electrically active defects will introduce an error in the simulation results, which will be discussed in further sections. Thus, the quantity $\Delta n_{1}$ can be defined as such a concentration, which was formed in a semiconductor due to heating in the temperature range $T_{\mathrm{cool}}-T_{\mathrm{cr}}$. When the temperature reaches $T_{\mathrm{cr}}$, there is an abrupt increase in the electron concentration by an amount of $\Delta n_{2}$ due to the ionization of $\mathrm{Fe}^{2+}$ form. In this case, we can approximately assume that:

$$
\Delta n_{2}=\left[\mathrm{Fe}^{2+}\right]
$$

This time dependence of the carrier concentration will affect the appearance of the potential difference, since the sample is non-uniformly doped with mixed-valence impurities. The following effects can occur:

- In the region of the sample, where mixed-valence impurities are contained, an excess local concentration of electrons or holes arises that creates a gradient leading to the generation of an electric current. This process leads to the appearance of an opposing field with a potential difference $U$.

- $\quad$ As $\mathrm{ZnO} / \mathrm{ZnO}-\mathrm{Me}$ samples are $n-n^{+}$-transition $(\mathrm{Me}=\mathrm{Fe})$ or $n-p$-transition $(\mathrm{Me}=\mathrm{Cu})$, then the appearance of additional charge carriers charges $n^{+}$-area negatively (in case of $\mathrm{ZnO} / \mathrm{ZnO}-\mathrm{Fe}$ ), and $p$-area positively (in case of $\mathrm{ZnO} / \mathrm{ZnO}-\mathrm{Cu}$ ). This means that both transitions are in forward bias, which is equivalent to applying direct voltage. Thus, some effective value of voltage will be formed on the sample, which is removed by a voltmeter.

To increase the reliability of the developed physical mechanisms, we consider quantitatively the occurrence of the thermovoltaic effect in $\mathrm{ZnO} / \mathrm{ZnO}-\mathrm{Fe}$ and $\mathrm{ZnO} / \mathrm{ZnO}-\mathrm{Cu}$ systems. First, let us analyze the possibility of the occurrence of an isostructural semiconductor-metal phase transition in the $\mathrm{ZnO}-\mathrm{Fe}$ system.

Iron ions form a solid substitutional solution in zinc oxide, displacing zinc cations into the interstices. According to X-ray absorption spectroscopy, zinc oxide coexists with $\mathrm{Fe}^{2+}$ and $\mathrm{Fe}^{3+}$ states in the ratio of 3:7, i.e., $\mathrm{Fe}^{3+}$ state is preferential [20]. Ions of $\mathrm{Fe}^{3+}$ are a donor impurity with ionization energy of $\sim 400 \mathrm{meV}$, and the energy level of $\mathrm{Fe}^{2+}$ is located near the Fermi energy of the semiconductor. When a high concentration of donor impurity is introduced into the semiconductor, it is possible to 
obtain large concentrations of charge carriers that can screen the core charge of impurity atoms, which will facilitate a collective transition of electrons from the level of $\mathrm{Fe}^{2+}$ :

$$
\mathrm{Fe}^{2+} \rightarrow \mathrm{Fe}^{3+}+\mathrm{e}^{-}-\Delta Q^{\prime}
$$

where $\Delta Q^{\prime}$ is the heat absorbed during the transition. This process is possible in the case when the Debye shielding radius $r_{\mathrm{S}}$ becomes less than the Bohr radius $r_{\mathrm{B}}$ of electron localization:

$$
r_{\mathrm{S}}<r_{\mathrm{B}}
$$

For convenience, all of the parameters that will be used in this article are summarized in Table 1.

Table 1. Important parameters.

\begin{tabular}{cccc}
\hline Symbol & Interpretation, Value & Symbol & Interpretation, Value \\
\hline$r_{\mathrm{S}}$ & Debye shielding radius $(\mathrm{m})$ & $h$ & Planck's constant, $6.62 \times 10^{-34} \mathrm{~J} \cdot \mathrm{s}$ \\
$r_{\mathrm{B}}$ & Bohr radius $(\mathrm{m})$ & $\hbar$ & Reduced Planck's constant, $1.054 \times 10^{-34} \mathrm{~J} \cdot \mathrm{s}$ \\
$\varepsilon$ & Permittivity & $m_{n}^{*}$ & Effective electron mass \\
$\varepsilon_{0}$ & Dielectric constant, $8.85 \times 10^{-12} \mathrm{~F} / \mathrm{m}$ & $k_{\mathrm{b}}$ & Boltzmann's constant, $1.38 \times 10^{-23} \mathrm{~J} / \mathrm{K}$ \\
$\tau_{n}$ & Chemical potential of electrons $(\mathrm{eV})$ & $T$ & Absolute temperature, $[\mathrm{K}]$ \\
$n$ & Electron concentration $\left(\mathrm{m}^{-3}\right)$ & $N_{\mathrm{D}}$ & Concentration of donor impurities, $\left[\mathrm{m}^{-3}\right]$ \\
$q$ & Electron charge, $1.6 \times 10^{-19} \mathrm{C}$ & $E_{\mathrm{D}}$ & Donor level ionization energy, $[\mathrm{eV}]$ \\
\hline
\end{tabular}

The Debye shielding radius is found from the relation [21]

$$
r_{\mathrm{S}}=\sqrt{\frac{2 \varepsilon \varepsilon_{0} \zeta_{n}}{3 n q^{2}}}
$$

Considering Equation (3) and

$$
r_{\mathrm{B}}=\frac{4 \pi \varepsilon \varepsilon_{0} \hbar^{2}}{m_{n}^{*} q^{2}}
$$

then the condition for the appearance of a transition "insulator-metal" in a semiconductor can be written as:

$$
\frac{4 \pi \varepsilon \varepsilon_{0} \hbar^{2}}{m_{n}^{*} q^{2}}=\sqrt{\frac{\varepsilon \varepsilon_{0} \zeta_{n}}{n q^{2}}}
$$

To calculate the chemical potential $\zeta_{n}$, it is necessary to take into account the high concentration of impurities in the resulting film $\mathrm{ZnO}-\mathrm{Fe}\left(3\right.$ at.\% Fe-1.2 $\left.\times 10^{21} \mathrm{~cm}^{-3}\right)$, which leads to a difference in the electron energy distribution from the Maxwell-Boltzmann distribution, being a particular case of Fermi-Dirac statistics. Therefore, we will find $\zeta_{n}$ by a numerical method using the electroneutrality equation. To do this, we will make a number of approximations: the concentration of intrinsic electrically active donor defects will be assumed to be negligibly small in comparison with the donor impurity concentration; we will neglect the minority charge carriers; we will only consider electronic transitions from the donor level to the semiconductor conduction band. In this case, the electroneutrality equation can be written as: $n=N_{\mathrm{D}}^{+}$. Then, the electron concentration can be written in the following form:

$$
n=N_{C} F_{1 / 2}\left(\frac{\zeta_{n}}{\mathrm{k}_{\mathrm{b}} T}\right)
$$

where

$$
N_{\mathrm{C}}=2\left(\frac{2 \pi m_{n}^{*} \mathrm{k}_{\mathrm{b}} T}{h^{2}}\right)^{3 / 2}
$$


is the effective density of states in the conduction band of a semiconductor;

$$
F_{1 / 2}\left(\zeta_{n}\right)=\frac{2}{\sqrt{\pi}} \int_{0}^{\infty} \frac{t^{1 / 2} d t}{1+\exp \left(t-\zeta_{n} / \mathrm{k}_{\mathrm{b}} T\right)}
$$

is the Fermi-Dirac integral with an index of $1 / 2$ [21]. Taking into account that the concentration of ionized donors can be found from the expression [21]

$$
N_{\mathrm{D}}^{+}=N_{\mathrm{D}}\left(1-\frac{1}{1+1 / 2 \exp \left(\frac{E_{\mathrm{D}}-\zeta_{n}}{\mathrm{k}_{\mathrm{b}} T}\right)}\right)
$$

the calculation of the temperature dependence of the chemical potential is reduced to a numerical solution of the integral equation:

$$
\frac{4}{\sqrt{\pi}}\left(\frac{2 \pi m_{n}^{*} \mathrm{k}_{\mathrm{b}} T}{h^{2}}\right) \int_{0}^{\infty} \frac{t^{1 / 2}}{1+\exp \left(t-\zeta_{n} / \mathrm{k}_{\mathrm{b}} T\right)}=N_{D}\left(1-\frac{1}{1+1 / 2 \exp \left(\frac{E_{\mathrm{D}}-\zeta_{n}}{\mathrm{k}_{\mathrm{b}} T}\right)}\right)
$$

On the basis of the arguments obtained, we calculate the dependence of the Debye shielding radius in the $\mathrm{ZnO}-\mathrm{Fe}$ system on the temperature for different values of donor impurity concentrations. Figure 3, illustrates the obtained dependences. The analysis shows that, in the investigated temperature range, in this system the transition "insulator-metal" only occurs at very high impurity concentrations. Thus, when $N_{\mathrm{D}}=10^{22} \mathrm{~cm}^{-3}$, the transition temperature will be $573 \mathrm{~K}$, and at lower concentrations, the temperature will exceed $700 \mathrm{~K}$. The threshold electron concentration required for the transition is $\sim 10^{-19} \mathrm{~cm}^{-3}$. Nevertheless, the obtained electron concentrations necessary for the phase transition are some average values. As in any disordered system, there are impurity fluctuations that determine the deviation from this mean value. This means that at first the transition occurs in local regions that are characterized by the maximum concentration at temperatures lower than those corresponding to the transition "insulator-metal" for averaged concentrations. Apparently, these processes explain the occurrence of the thermovoltaic effect in the $\mathrm{ZnO}-\mathrm{Fe}$ system at temperatures lower than the calculated ones. With increasing temperature, the dimensions of these regions will grow and lead to the formation of a percolating spanning cluster, when the phase transition covers the entire volume of the material. Also, the contribution to the difference between theoretical and experimental values of the critical temperatures at which the generation of the electromotive force begins is made by other factors that were not taken into account in our quantitative model. First of all, it is the presence of its own electrically active defects in zinc oxide, namely, vacancies in the oxygen sublattice, which act as donors. Their ionization during heating of the system leads to the appearance of a critical concentration of electrons at temperatures that are lower than the calculated ones. It should also be understood that the films are not a single-crystal $\mathrm{ZnO}$ sample, but a branched polycrystalline fractal structure actively interacting with the environment. The interaction process leads to the appearance of chemisorbed forms of negatively charged oxygen, the presence of which forms depleted layers on the surface of an $n$-type semiconductor. Nevertheless, the obtained values of the critical temperatures at which the generation of the electromotive force occurs, even within such simple approximations, coincide in order with the experimental data, which confirms the value of the developed concepts. 


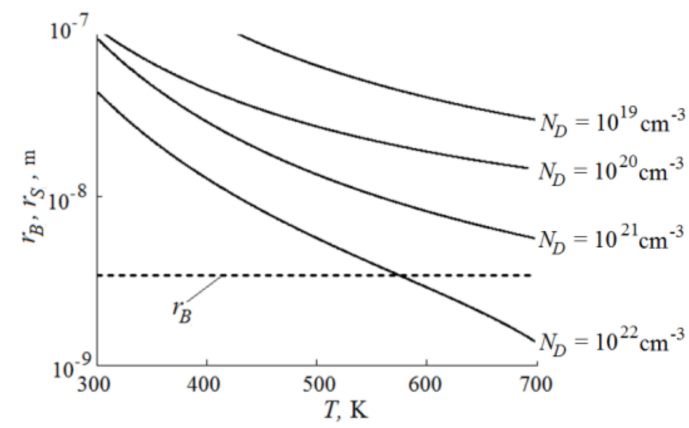

(a)

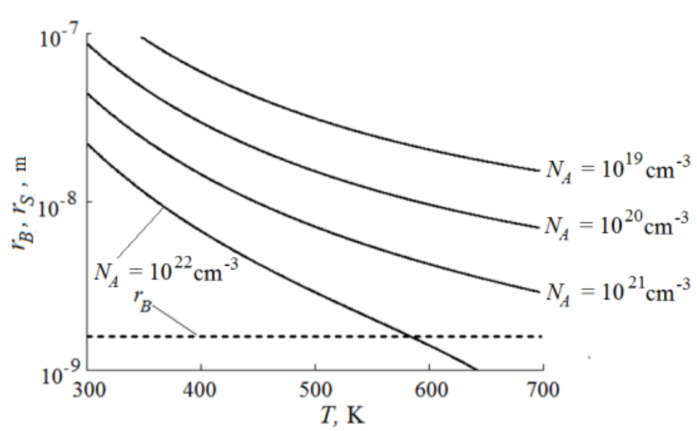

(b)

Figure 3. (a) Temperature dependence of the Debye shielding radius in the $\mathrm{ZnO}-\mathrm{Fe}$ system with different iron concentrations; (b) temperature dependence of the Debye shielding radius in the $\mathrm{ZnO}-\mathrm{Cu}$ system with different copper concentrations.

Let us now consider the possibility of the occurrence of an isostructural semiconductor-metal phase transition in the $\mathrm{ZnO}-\mathrm{Cu}$ system. Copper is an acceptor impurity in zinc oxide. When a solid substitutional solution is formed, copper $\mathrm{Cu}^{+}$cations displace $\mathrm{Zn}^{2+}$ into interstices and act as acceptors with ionization energy of $369 \mathrm{meV}$. A small number of $\mathrm{Cu}^{+}$cations occupy positions in the interstices of the crystal lattice, playing the role of donor impurities with activation energy of $109 \mathrm{meV}$. The $\mathrm{Cu}^{2+}$ state is $200 \mathrm{meV}$ lower the bottom energy of the conduction band [22].

Carrying out a simulation that is similar to the $\mathrm{ZnO}-\mathrm{Fe}$ system, we obtain the results that are presented in Figure 3b. It can be seen that the obtained dependences are analogous to $\mathrm{ZnO}-\mathrm{Fe}$. Nevertheless, an important feature of the results should be noted. Since the activation energies of Fe and $\mathrm{Cu}$ impurity atoms are practically the same, the main contribution to system differences is made by the difference in the effective masses of electrons and holes in zinc oxide. Since the effective mass of holes in zinc oxide is greater than the effective mass of an electron, an increase in the concentration of free charge carriers with increasing temperature is faster. It should be expected that the transition "insulator-metal" in the system would occur at lower temperatures than for the $\mathrm{ZnO}-\mathrm{Fe}$ system, where the main carriers are electrons. However, for the concentration of the acceptor impurity of $10^{22} \mathrm{~cm}^{-3}$, the transition occurs at $584 \mathrm{~K}$, which is higher than for $\mathrm{ZnO}-\mathrm{Fe}$ at the same donor concentration. This is due to the decrease in the Bohr radius in $\mathrm{ZnO}-\mathrm{Cu}$ related to the higher effective mass of holes in $\mathrm{ZnO}$.

Thus, the calculation of the temperature of the occurrence of the thermovoltaic effect within the framework of the developed simple physical mechanisms in $\mathrm{ZnO}-\mathrm{Cu}$ and $\mathrm{ZnO}-\mathrm{Fe}$ systems describes the experimental results obtained quite well. Firstly, it is shown that in the $\mathrm{ZnO}-\mathrm{Cu}$ system the critical temperature of the electric voltage generation will be higher than in the $\mathrm{ZnO}-\mathrm{Fe}$ system. Secondly, the obtained absolute temperature values are close to the experimental values (especially for the $\mathrm{ZnO}-\mathrm{Cu}$ system). The reasons for the lower temperatures of the beginning of generation in comparison with the calculated ones are considered above.

A logical development of the proposed model will be taking into account the effect of the own point electrically active defects in the material on the values of the critical temperature at which the "insulator-metal" transition occurs. However, it should be noted that this is not an easy task. As it was shown in [15], the total concentration of free charge carriers is not an additive sum of ionized forms of impurities and defects, and there is an effect of external doping on the ionization efficiency of oxygen vacancies. In the first approximation, when developing a more accurate model, one can use ideas about the change in number of ionized point defects when the Fermi level changes position in a semiconductor. Defective states in zinc oxide have several levels in the forbidden zone [23]. Therefore, the predominant form of the charge will be determined by the position of the Fermi level, which depends on the doping level of the semiconductor. It should also be noted the possibility of the formation of clusters of charged defect and impurity states in the semiconductor. At the same time, at some annealing temperatures, oppositely charged defects diffuse to each other, forming clusters, which 
significantly affect the electrophysical properties of the material, including the energy of the defect states themselves. The development of these physical mechanisms is the subject of our further research.

\subsection{Development of Physical Mechanisms of Temperature Dependence of the Electromotive Force Arising in} $\mathrm{Zn} / \mathrm{ZnO}-\mathrm{Me}$ Homojunctions

Let us analyze the experimentally obtained dependences in Figure 2, while taking into account the possibility of oxygen chemisorption on the surface of the films, as well as the mutual transition of various forms of chemisorbed oxygen with a change in temperature.

The EMF temperature dependence will increase linearly in the $200-300{ }^{\circ} \mathrm{C}$ range from 0 to $10 \mathrm{mV}$ for $\mathrm{ZnO} / \mathrm{ZnO}-\mathrm{Fe}$ samples, the upper layer of which is formed by three immersions. This dependence can be explained in the following way: in the semiconductor, as in any other disordered system, there are fluctuations in the impurity concentration characterizing the deviation from the mean value. At low temperatures, the semiconductor-metal transition will occur only in the local parts of the sample with the maximum value of the concentration of free electrons. As the temperature rises, the region of existence of the phase transition will grow, which is equivalent to an increase in the negative potential in the $\mathrm{ZnO}-\mathrm{Fe}$ region. Thus, an increase in temperature will lead to an increase in the electromotive force arising in homojunctions.

It can be seen from Figure 2 that the samples of $\mathrm{ZnO} / \mathrm{ZnO}-\mathrm{Fe}$, the upper layer of which is formed by two immersions, behave somewhat differently. The features of this series of samples include a change in the sign of the polarity of the emerging EMF, as well as a large deviation of its temperature dependence on the linear function.

The first feature, apparently, can be explained by a combination of various factors, the main of which are:

- Emergence of a potential barrier under point contact and the possibility of an inversion layer. In this case, the system becomes $n-n^{+}-p$, and in a certain temperature range the polarity of the EMF taken will be different. With increasing temperature due to ionization of the donor impurity, the inversion layer will decrease and disappear at some critical value. With further temperature growth, the $U(T)$ dependence will be close to the same dependence as for a series of samples, the upper layer of which is formed by three immersions;

- Probability of emergence of piezo-, flexo- and pyroelectric effects in zinc oxide films;

- Emergence of new phases on the surface of films (for example, copper and iron oxides), which can lead to the appearance of depleted, enriched or inversion layers at interfaces.

Nevertheless, despite a large number of factors capable of influencing the polarity and magnitude of the electromotive force arising in the samples, it should be understood that its very appearance cannot be explained by these effects. The fact is that pyro-, piezo-, flexoelectric, and other effects can occur in our samples during heating. However, after the establishment of thermal equilibrium at a given temperature, the resulting EMF should exponentially decay. In addition, we have short-circuited the output contacts, which should lead to the EMF relaxation. However, further measurements showed the restoration of the original value of the EMF. On the basis of these data, it can be concluded that the very appearance of the electromotive force in samples is only explained by the "dielectric-metal" transition. It should also be noted that when developing a model of the dependence of the output voltage on temperature, it is necessary to take into account the formation of $p-n$ and $n-n^{+}$junctions in our materials. However, this is beyond the scope of our work, since our model calculates only the critical temperature in the alloyed film, at which the "dielectric-metal" transition occurs, leading to the appearance of the EMF.

As it was shown earlier, the surface of the film formed by two immersions is more developed than the surface formed by three immersions for both $\mathrm{ZnO}-\mathrm{Fe}$ and $\mathrm{ZnO}-\mathrm{Cu}$ samples. On the basis of this, it can be assumed that the chemisorbed forms of oxygen will exert a stronger influence on the electrophysical properties of the samples in the first case. 
Oxygen, being an oxidizing gas, will carry out the capture of free electrons from the semiconductor, which will eventually lead to a decrease in the value of the electromotive force due to the thermovoltaic effect. There are two characteristic breaks at temperatures of $\sim 240$ and $280^{\circ} \mathrm{C}$ on the $U(T)$ dependence for the $\mathrm{ZnO} / \mathrm{ZnO}-\mathrm{Fe}$ samples, the upper layer of which is formed by two immersions. Apparently, their appearance corresponds to the processes of mutual transitions of various forms of chemisorbed oxygen, which can be accompanied by a sharp increase or a decrease in the concentration of free electrons in the semiconductor, manifested in a narrow temperature range [24]. It is likely that the main contribution to the presented dependences is made by the following processes $[25,26]$ :

$$
\begin{aligned}
& \mathrm{O}_{2(a d s)}^{-}+\mathrm{e}^{-} \rightarrow \mathrm{O}_{2(a d s)}^{2-}, 200^{\circ} \mathrm{C}<\mathrm{T}<300^{\circ} \mathrm{C} \\
& \mathrm{O}_{2(a d s)}^{-}+\mathrm{e}^{-} \rightarrow 2 \mathrm{O}_{(a d s)}^{-}, T>350^{\circ} \mathrm{C} \\
& \mathrm{O}_{2(a d s)}^{2-} \rightarrow 2 \mathrm{O}_{(a d s)}^{-}, T>350^{\circ} \mathrm{C}
\end{aligned}
$$

The EMF temperature dependences for $\mathrm{ZnO} / \mathrm{ZnO}-\mathrm{Cu}$ samples are, in fact, analogous to the same dependences for $\mathrm{ZnO} / \mathrm{ZnO}-\mathrm{Fe}$ samples. It is established that the semiconductor-metal transition in $\mathrm{ZnO}-\mathrm{Cu}$ system will occur at higher temperatures than in the analogous $\mathrm{ZnO}-\mathrm{Fe}$ system: the onset of EMF generation for $\mathrm{ZnO} / \mathrm{ZnO}-\mathrm{Cu}$ samples occurs at a higher temperature than for the $\mathrm{ZnO} / \mathrm{ZnO}-\mathrm{Fe}$ samples.

The $U(T)$ dependence for $\mathrm{ZnO} / \mathrm{ZnO}-\mathrm{Cu}$ samples, the upper layer of which is formed by three immersions, is close to linear. It should be noted that with the same configuration of the voltmeter contacts that was used in the $\mathrm{ZnO} / \mathrm{ZnO}-\mathrm{Fe}$ system, the EMF value will have the opposite sign, since $\mathrm{ZnO} / \mathrm{ZnO}-\mathrm{Cu}$ samples are of $n-p^{+}$structure, as shown in Figure 1.

The temperature dependence for $\mathrm{ZnO} / \mathrm{ZnO}-\mathrm{Cu}$ samples, the upper layer of which is formed by two immersions, changes the EMF sign. Apparently, this process can also be associated with phenomena under point contact, accompanied by the emergence of potential barriers and an inversion layer. A significant deviation of the dependence on the linear form at temperatures of $290-300{ }^{\circ} \mathrm{C}$ both for a given series of samples and for $\mathrm{ZnO} / \mathrm{ZnO}-\mathrm{Fe}$ samples can be due to mutual transitions of various forms of chemisorbed oxygen.

The approaches that were developed in this work can be useful for explaining the thermovoltaic effect in a wide range of materials, for example, in germanium-silicon films heavily doped with titanium [27], variable-gap solid solutions of $\mathrm{Si}_{x} \mathrm{Ge}_{1-x}$ [11], in which this effect has been detected in recent years.

\section{Conclusions}

Thus, a model for the emergence of a thermovoltaic effect in zinc oxide non-uniformly doped with mixed-valence impurities has been developed in the article. $\mathrm{ZnO} / \mathrm{ZnO}<\mathrm{Cu}$, Fe $>$ transitions, obtained by the sol-gel method, were used as laboratory samples, resulting in a stepwise distribution of the impurity in the sample. It is known from the work of other scientific groups that the impurities are in two charge states in the sample, the main of which is a donor $\left(\mathrm{Fe}^{3+}\right)$, or an acceptor $\left(\mathrm{Cu}^{+}\right)$. With increasing temperature, the concentration of free carriers increases due to the ionization of donor and acceptor forms of impurities, as well as its own point electrically active defects, which leads to a screening of the core charge of the impurity ions in the minority charge state under critical conditions. This leads to an abrupt endothermic ionization process of multivalent impurities takes place, accompanied by the appearance of a concentration gradient of free carriers in the sample, and, accordingly, the emergence of an electromotive force. The influence of oxygen chemisorbed on the surface of the films was also taken into account within the framework of the developed physical mechanisms. Quantitative calculations of the critical temperature at which the thermovoltaic effect occurs in the framework of the developed models describe the obtained experimental results quite well.

The results that were obtained can be used in the development of new generation heat energy converters. It is well known that the efficiency of such converters reaches record highs. For example, 
for a semiconductor SmS typical values are 17\%-36\% [28]. The main advantage of such structures is the generation of electrical power during heating without a temperature gradient. Therefore, calculation of the efficiency of converters based on the developed samples is the future perspective of our work.

Author Contributions: Conceptualization, I.P. and V.M.; Formal Analysis, I.A. and V.M.; Investigation, I.P. and N.Y.; Methodology, D.D.; Software, A.K.; Visualization, A.K.; Writing-Original Draft Preparation, I.P and N.Y.; Writing-Review and Editing, I.P. and D.D.

Funding: This work was funded by the Ministry of Education and Science of the Russian Federation (No. 16.897.2017/4.6).

Acknowledgments: All of the authors are thankful to G. Vishnevskaya (Penza State University) for careful reading of the manuscript.

Conflicts of Interest: The authors declare no conflict of interest.

\section{References}

1. Kazanin, M.M.; Kaminskiǐ, V.V.; Solovev, S.M. Anomalous thermal electromotive force in samarium monosulfide. Tech. Phys. 2000, 45, 659-661. [CrossRef]

2. Takahashi, T.; Yamada, O. Mechanism of voltage generation during phase change of FeS single crystals. J. Phys. Chem. Solids 1976, 37, 161-165. [CrossRef]

3. Kaminskii, V.V.; Kazanin, M.M.; Klishin, A.N.; Solov'ev, S.M.; Golubkov, A.V. Thermovoltaic effect in samarium sulfide-based heterostructures. Tech. Phys. 2011, 56, 893-895. [CrossRef]

4. Johnson, A.D.; Katz, P.I. Spontaneous EMF associated with shape memory effect in TiNi. J. Appl. Phys. 1977, 48, 73-74. [CrossRef]

5. Zou, M.; Sampaio, J.A.; Pecharsky, V.K.; Gschneidner, K.A. Spontaneous generation of voltage in the magnetocaloric compound $\mathrm{La}\left(\mathrm{Fe}_{0.88} \mathrm{Si}_{0.12}\right)_{13}$ and comparison to $\mathrm{SmMn}_{2} \mathrm{Ge}_{2}$. Phys. Rev. B 2009, 80, 172403. [CrossRef]

6. Abramovich, A.I.; Koroleva, L.I.; Dolzhenkova, Y.V.; Shimchak, R. Spontaneous generation of the electrical voltage in charge-ordered manganite $\operatorname{Pr}_{0.6} \mathrm{Ca}_{0.4} \mathrm{MnO}_{3}$. Phys. Solid State 2014, 56, 496-500. [CrossRef]

7. Karapetyan, G.Y.; Parinov, I.A.; Runkevich, N.S.; Parchi, G. Thermovoltaic effect in field effect metal-dielectric-semiconductor-metal structure. In Advanced Materials, 1st ed.; Parinov, I.A., Chang, S.-H., Jani, M.A., Eds.; Springer: Cham, Switzerland, 2017; Volume 193, pp. 219-227.

8. Pronin, I.A.; Averin, I.A.; Karmanov, A.A.; Yakushova, N.D.; Bozhinova, A.S.; Dimitrov, D.T.; Papazova, K.I.; Georgieva, A.T.; Moshnikov, V.A.; Terukov, E.I. The thermovoltaic effect in zinc oxide inhomogeneously doped with mixed-valence impurities. Tech. Phys. Lett. 2015, 41, 930-932. [CrossRef]

9. Dimitrov, D.T.; Nikolaev, N.K.; Papazova, K.I.; Krasteva, L.K.; Pronin, I.A.; Averin, I.A.; Bojinova, A.S.; Georgieva, A.T.; Yakushova, N.D.; Peshkova, T.V. Investigation of the electrical and ethanol-vapour sensing properties of the junctions based on $\mathrm{ZnO}$ nanostructured thin film doped with copper. Appl. Surf. Sci. 2017, 392, 95-108. [CrossRef]

10. Kalinin, Y.E.; Makagonov, V.A.; Pankov, S.Y.; Sitnikov, A.V. Electrical properties of bilayer thin-film $\mathrm{ZnO} / \mathrm{ZnO}-F e$ structures. Vestnik of Voronezh State Technical University 2016, 12, 66-70. (In Russian)

11. Saidov, A.S.; Leyderman, A.Y.; Karshiev, A.B. The thermovoltaic effect in variband solid solution $\mathrm{Si}_{1-x} \mathrm{Ge}_{x}$ $(0 \leq x \leq 1)$. Tech. Phys. Lett. 2016, 42, 725-728. [CrossRef]

12. Leyderman, A.Y.; Saidov, A.S.; Karshiev, A.B. The thermoelectric effect in a graded-gap $n \mathrm{Si}_{-}-p \mathrm{Si}_{1-x} \mathrm{Ge}_{x}$ heterostructure. Appl. Sol. Energy 2016, 52, 115-117. [CrossRef]

13. Egorov, V.M.; Kaminskii, V.V.; Kazanin, M.M.; Solov'ev, S.M.; Golubkov, A.V. Efficiency of transformation of heat energy into electric energy due to the thermovoltaic effect. Tech. Phys. Lett. 2013, 39, 650-652. [CrossRef]

14. Mott, N.F. Metal-Insulator Transition; Taylor \& Francis: London, UK, 1974; p. 296.

15. Bhosle, V.; Tiwari, A.; Narayan, J. Metallic conductivity and metal-semiconductor transition in Ga-doped ZnO. Appl. Phys. Lett. 2006, 88, 032106. [CrossRef]

16. Kumar, R.; Singh, A.P.; Thakur, P.; Chae, K.H.; Choi, W.K.; Angadi, B.; Kaushik, S.D.; Patnaik, S. Ferromagnetism and metal-semiconducting transition in Fe-doped ZnO thin films. J. Phys. D Appl. Phys. 2008, 41, 155002. [CrossRef] 
17. Shao, J.; Dong, W.; Li, D.; Tao, R.; Deng, Z.; Wang, T.; Meng, G.; Zhou, S.; Fang, X. Metal-semiconductor transition in $\mathrm{Nb}$-doped $\mathrm{ZnO}$ thin films prepared by pulsed laser deposition. Thin Solid Films 2010, 518, 5288-5291. [CrossRef]

18. Kaminskii, V.V.; Vasil'ev, L.N.; Romanova, M.V.; Solov'ev, S.M. The mechanism of the appearance of an electromotive force on heating of sms single crystals. Phys. Solid State 2001, 43, 1030-1032. [CrossRef]

19. Jiang, Y.; Giles, N.C.; Halliburton, L.E. Persistent photoinduced changes in charge states of transition-metal donors in hydrothermally grown ZnO crystal. J. Appl. Phys. 2007, 101, 093706. [CrossRef]

20. Chen, T.; Cao, L.; Zhang, W.; Zhang, W.; Han, Y.; Zheng, Z.; Xu, F.; Kurash, I.; Qian, H.; Wang, J.O. Correlation between electronic structure and magnetic properties of Fe-doped ZnO films. J. Appl. Phys. 2012, 111, 123715. [CrossRef]

21. Tauc, J. Photo and Thermoelectric Effects in Semiconductors; Pergamon Press: Oxford, UK, 1962; p. 248.

22. He, H.; Li, S.; Sun, L.; Ye, Z. Hole traps and Cu-related shallow donors in ZnO nanorods revealed by temperature-dependent photoluminescence. Phys. Chem. Chem. Phys. 2013, 15, 7484-7487. [CrossRef] [PubMed]

23. Kohan, A.F.; Ceder, G.; Morgan, D.; Van de Walle, C.G. First-principles study of native point defects in ZnO. Phys. Rev. B 2000, 61, 15019. [CrossRef]

24. Nimbalkar, A.R.; Patil, M.G. Synthesis of $\mathrm{ZnO}$ thin film by sol-gel spin coating technique for $\mathrm{H}_{2} \mathrm{~S}$ gas sensing application. Phys. B Condens. Mater. 2017, 527, 7-15. [CrossRef]

25. Sysoev, V.V. Multisensory Gas Recognition Systems Based on Metal Oxide Thin Films and Nanostructures. Ph.D. Thesis, Yuri Gagarin State Technical University of Saratov, Saratov, Russia, October 2009. (In Russian)

26. Averin, I.A.; Pronin, I.A.; Yakushova, N.D.; Goryacheva, M.V. The volt-ampere characteristics of resistive gas sensors in multisensor implementation: Distinctive features. Autom. Remote Control 2014, 75, 2034-2040. [CrossRef]

27. Kuchkanov, S.K.; Ashurov, K.B. Generation of charge carriers in uniformly heated Si-Ge films heavily doped with titanium. Tech. Phys. Lett. 2018, 44, 334-336. [CrossRef]

28. Egorov, V.M.; Kaminskii, V.V.; Kazanin, M.M.; Solov'ev, S.M.; Golubkov, A.V. The efficiency of thermal energy conversion into electricity by means of the thermovoltaic effect. Tech. Phys. Lett. 2015, 41, 381-382. [CrossRef] 